\title{
Ornithology and varieties of conflict: A personal retrospective on conflict forecasting
}

Kristian Skrede Gleditsch, University of Essex \& Peace Research Institute Oslo

ksg@essex.ac.uk

This note - based on reflections around the retirement of Professor Michael D. Ward from Duke University - provides some personal thoughts on conflict forecasting and what we have learned in retrospective.

The failure to anticipate big transformative events such as the end of the Cold War motivated a debate on the predictive ability of dominant social science theories (see, e.g., Gaddis 1992/1993; Hechter et al. 1995). The initial contributions highlighting apparent failures stimulated some interesting responses on what one could do instead. Some proposed generative models that can reproduce the observed outcomes (see e.g. Kuran 1989; Lohmann 1994), while others pointed to how existing theories could be used to produce better forecasts (Ray and Russet 1996). However, there was very little by way of actual forecasting.

It is certainly true that many of theories criticized had severe flaws, and perhaps often tended to assume that the future could be projected in a simple manner from the past. Learning after the fact can obviously be helpful for enhancing our understanding of phenomena and new theory development, but is not really a persuasive proof of the ability to forecast, unless actually produced ex ante. I am reminded of the infamous quote on the 2008 US democratic nomination popularized by Andrew Gelman that "[b]ut viewed in retrospect, it is clear that it has been quite predictable" (see http://andrewgelman.com/2008/06/but_viewed_in_r). Can something be claimed to be predictable unless predicted in advance?

But there is a deeper first lesson here: Focusing on the big transformative events is a humble reminder of the limits to our ability to predict and anticipate, but not a good approach to evaluating our overall predictive abilities or the utility of forecasts in general. Looking only at the big surprising events or the "black swans" (as popularized by Taleb 2007) can make us lose focus on the much bigger population of white swans, and the many regularities in their behavior or whereabouts at specific time points. Swans of distinct colors are clearly different and have very different population 
shares, but just as it is important to acknowledge highly improbably outcomes that are difficult to predict ex ante, identifying "modal range" outcomes that are more regular and easier to predict can be just as important for many purposes. Analyses should both be explicit on their main purpose as well as identifying what is relatively easier or harder to predict, and criticisms of forecasting should not use evidence on the latter to obscure evidence on the former.

The current interest in what Ward et al. (2013) have called "the new generation of conflict prediction", focusing on out-of-sample prediction of conflict, in many ways originated with the article by Beck et al. (2000) applying neural network to dyadic models of militarized interstate conflict. Using training data for 1947-85 and predicting out-of-sample to the subsequent interval 1986-89, the authors noted that existing logit models did not assign any of the conflicts occurring over the period probabilities above 0.5 while the neural network approach did so in $16.9 \%$ of the conflict cases. However, the actual events predicted by the model turned out to be fairly obscure, typically new incidents in some ongoing territorial disputes, and hardly the modern equivalent of the Cuban Missile Crisis.

There is a second important lesson here: A model can only be expected to predict if it has some factors plausibly related to the causes of conflict. Beck et al. basically estimated a version of the Oneal and Russett (2001) liberal peace model, focusing on how a series of liberal factors would make conflict less likely. However, the underlying dyadic risk of conflict or the origins of conflict is treated as largely exogenous in this framework. This may be a perfectly valid approach to testing whether liberal dyads are more pacific, but we should not expect it to be a good model for forecast - a completely different purpose than what it was originally devised for.

Ward and Gleditsch (2002) examine how spatial features and diffusion can improve conflict forecasts as examples of plausible influences that can be observed ex ante. Other factors reflecting motives for conflict can be useful to identify differences in risk and improve forecasting (se Buhaug et al. 2014; Cederman et al. 2013). Gleditsch and Ward (2013) showed how focusing on contentious issues and how these are managed could improve forecasts of interstate conflict, although the availability of data currently limits the ability to conduct such forecasts. 
A large body of research has showed ways to improve predictive models of conflict in through avenues such as improved attention to factors reflecting motives, autoregressive trends and the tendency for conflict events to recur, as well as networks structure and spatial patterns (see Hegre et al. 2017; Ward et al 2013 for reviews). Forecasting is also often a more useful form of theory evaluation, by evaluating propositions on genuinely new data, that guards against the temptation to overfit to the observed data. Popper's (1959) core point that the context of verification should be independent from the context of discovery often seems to be forgotten in much empirical work.

In sum, although forecasting is difficult, especially about the future, existing research demonstrates that much can be forecast, and that forecasting also can serve as an important check on theory evaluation. However, there are different types of events and forecasts and some are more difficult to do than others. In general, predicting recurrent events in a conflict prone relationship will be much easier than predicting surprising new events. Researchers should take pride in what they can do well and be explicit but not defensive about the taller orders.

The enduring relevance of many of the above lessons is also apparent in recent discussions of conflict trends and risks. Many argue that there has been a clear decline in violence (Goldstein 2011; Gurr 2000; Pinker 2011), while critics argue that features of severity-frequency distribution and the timing of conflicts make it impossible to reject the null hypothesis of no underlying change in the risk of severe wars without a much longer period without major world wars (see Cirillo and Taleb 2017; Clauset and Gleditsch 2017). The latter argument is often seen as inherently undermining any possibility of forecasts. But there is no inherent contradiction in acknowledging that it is difficult to say something about the risk of very large events, and that we can still make useful predictions about profiles of actor or locations with a higher risk of conflict. We may not be able to offer very precise predictions of how implausible a new World War III would be over the next 100 years based on the existing data and models. However, if we can predict some of the smaller events likely to occur over a shorter future time interval and more precise locations, then this is clearly valuable in its own right and also more useful for many purposes.

Some concede that conventional war may have declined, but argue that other forms of violence such as terrorism have increased. Although some data suggest an increase in terrorism (e.g., Global Terrorism Index 2015), it can be shown that most terrorist attack actually occur within countries that 
already experience conventional conflicts, such as for example Afghanistan and Iraq. There may be many reasons why terrorism is used more intensively within current civil wars (see Polo and Gleditsch 2016 for a review of rebel characteristics and use of terrorism). But if the increase in terrorism occurs primarily within conventional conflicts then it cannot convincingly be claimed to undermine the case for a decline in conventional civil conflict.

However, even if terrorism has not clearly increased outside civil war, one may ask whether terrorism outside civil war plausibly differ from terrorism within civil war. For example, is terrorism outside civil wars more such as IS attacks in the West are less frequent in numbers but on average more severe, as suggested by some observers that see terrorism as a highly unpredictable "existential threat". Data and models can serve as check on popular perceptions and a useful way to think about risks. It can be shown that terrorism like many other conflict data can be follow so-called power laws, where the frequency of an event is an inverse power of severity (see Clauset et al 2007; Richardson 1948). More formally, the frequency of events of a given severity $\mathrm{x}$ scale as $P(x) \propto x^{-\alpha}$, where $\alpha$ indicates the relative frequency of the more severe events, with severity typically measured by the number of deaths for conflict data. Hence, the lower the $\alpha$, the more likely are the larger events given their frequency, and the more worried we should be about the impact of potential catastrophes (see Hanson 2008). Gleditsch et al. (2017) shows that the scaling coefficient for terrorism outside civil ( $\alpha \approx 2.48$ ) seems somewhat lower than within civil wars ( $\alpha \approx 3.05$ ), or severe attacks are relatively outside civil wars given the frequency of attacks. However, the powers are still relatively high in comparison to other forms of disasters, far from the threshold of powers below 1 where Hanson (2008) suggests one should be willing to spend proportionally far more to prevent and respond to the very large events. 


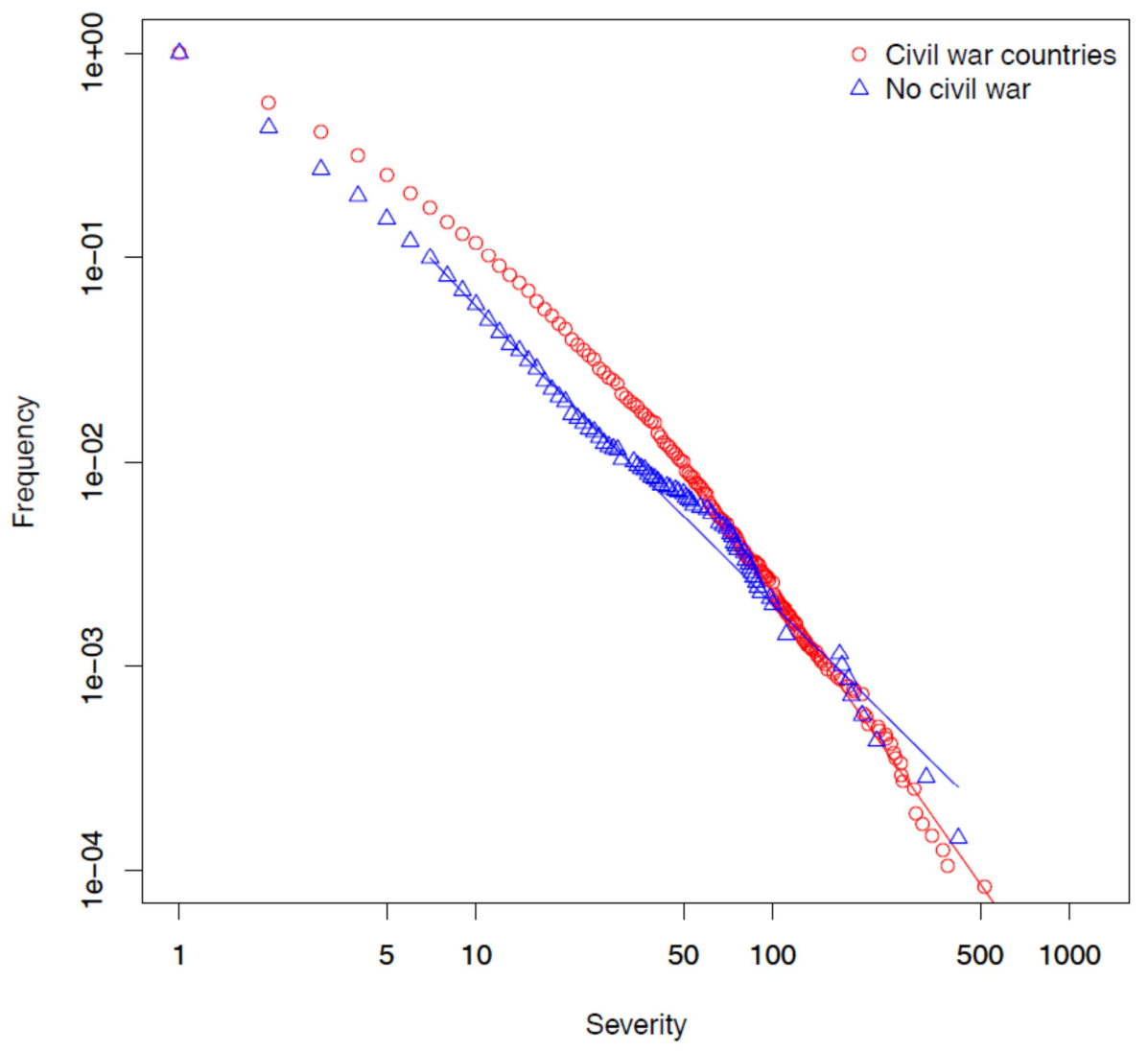

Figure 1: The frequency-severity distribution for attacks and associated casualties in the Global Terrorism Database (http://www.start.umd.edu/gtd/), separating by location in countries with and without an ongoing armed civil conflict in the Uppsala Armed Conflict Data (http://ucdp.uu.se/), from Gleditsch et al (2017). The overall volume of terrorism is much lower outside civil war, both in terms of absolute frequency or total deaths, but the more severe individual attacks are plausibly relatively more frequent outside civil war.

The attacks patters of groups outside civil war are likely to more difficult to detect, since groups rely more on covert planning and carry out fewer attacks (see Clauset et al. 2007). But this does not mean that all the terrorism that we should care about cannot be forecast. The largest impact of surprising terrorist attacks stems from the responses they generate rather than the deaths or direct impact of the attacks themselves (see Mueller and Stewart 2015). If we care about the overall number of attacks and deaths then we should care about terrorism in civil war, which is likely to be much more frequent and displaying regular patterns that are easier to predict. Research indicated that ethnic terrorism can be reduced through forms of ethnic accommodation and concessions in much the same way as civil wars (see Gleditsch and Polo 2016). Even IS itself originated out of civil wars in the Middle East. Thus, understanding the relationship between civil war, terrorism, and the 
diffusion of violence elsewhere may ultimately have bigger payoffs than focusing exclusively on preventive measures that have been shown to have low cost effectiveness (Mueller and Stewart 2011).

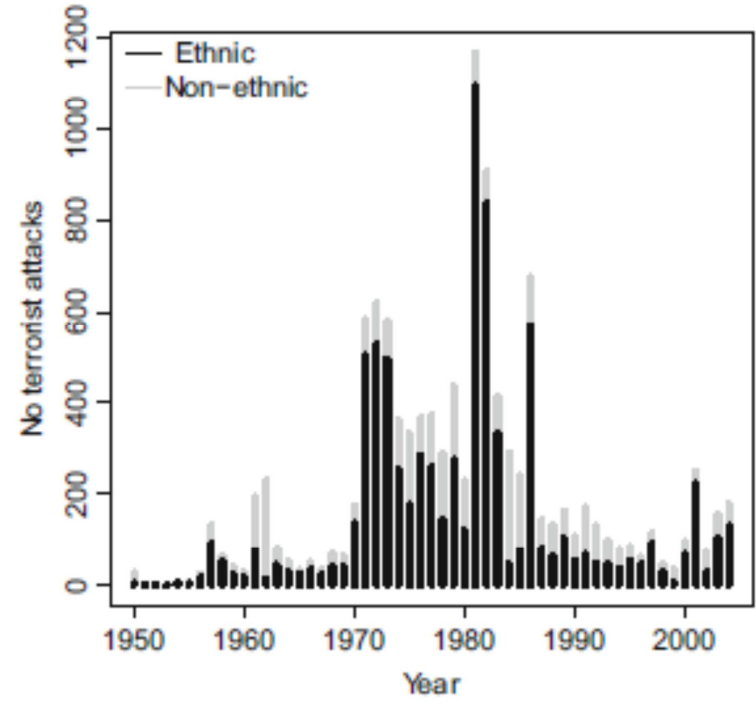

(a)

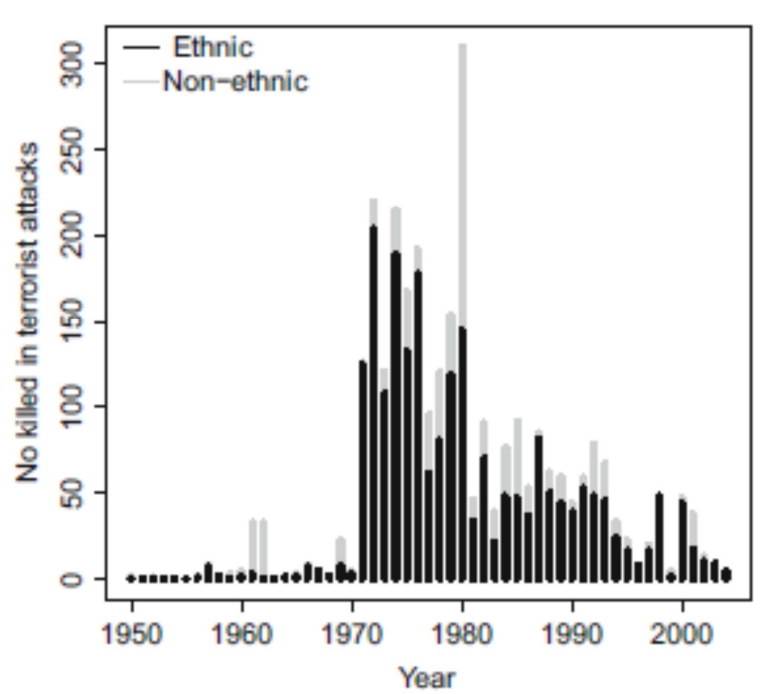

(b)

Figure 2: Terrorist attacks in Western Europe by type, based on the Terrorism in Western Europe Database (Engene 2007), by a) events and b) total deaths in attacks, adapted from Gleditsch and Polo (2016).

The disproportionate attention to the failures of forecasting spectacular events reminds us about what we do not know and what is hard to predict. However, much has been learned about forecasting the other end of the distribution, and the gains that plausibly can be made. And even when we cannot forecast something we can surely learn much more if we focus on the specific things that limit our ability than just throwing our hands up in the air. One of many things that I have learned from working with Mike Ward is that perseverance and not giving up at the first hurdle is key, and this has clearly paid off in work on forecasting conflict.

\section{References}

Beck, Nathaniel, Gary King, and Langche Zeng. 2000. Improving Quantitative Studies of International Conflict: A Conjecture. American Political Science Review 94 (1):21-36. 
Buhaug, Halvard, Lars-Erik Cederman, and Kristian Skrede Gleditsch. 2014. Square Pegs in Round Holes: Inequalities, Grievances, and Civil War. International Studies Quarterly 58 (2):418-31.

Cederman, Lars-Erik, Kristian Skrede Gleditsch, and Halvard Buhaug. 2013. Grievances and Inequality in Civil Wars. Cambridge and New York: Cambridge University Press.

Cederman, Lars-Erik, Kristian Skrede Gleditsch, and Julian Wucherpfennig. 2017. Predicting the Decline of Ethnic Civil War: Was Gurr Right and For the Right Reasons? Journal of Peace Research 54 (2):262-74.

Clauset, Aaron, Maxwell Young, and Kristian Skrede Gleditsch. 2007. On the Frequency of Severe Terrorist Events. Journal of Conflict Resolution 51 (1):1-31.

Cirillo, Pasquale, and Nassim Nicholas Taleb. 2016. On the statistical properties and tail risk of violent conflicts. Physica A: Statistical Mechanics and its Applications 452 (15):29-45.

Engene, Jan Oskar. 2007. Five Decades of Terrorism in Europe: The TWEED Dataset. Journal of Peace Research 44(1): 109-121

Gaddis, John Lewis. 1992/93. International Relations Theory and the End of the Cold War. International Security 17:5-58.

Gleditsch, Kristian Skrede, and Aaron Clauset. forthcoming. "Trends in Conflict: What Do We Know and What Can We Know?" In Oxford Handbook of International Security, ed. W. Wolforth and A. Gheciu. New York and Oxford: Oxford University Press.

Gleditsch, Kristian Skrede, and Sara MT Polo. 2016. Ethnic inclusion, democracy, and terrorism. Public Choice 169 (3):207-29.

Gleditsch, Kristian Skrede, Sara MT Polo, and Andrea Ruggeri. 2017. A transformation of political violence? The decline of conflict and terrorism. Paper presented at the annual meeting of the International Studies Association, Baltimore, MD 22-25 February.

Gleditsch, Kristian Skrede, and Michael D Ward. 2013. Forecasting is difficult, especially about the future: Using contentious issues to forecast interstate disputes. Journal of Peace Research 50 (1):1731.

Global Terrorism Index. 2015. Sydney: Institute for Economics and Peace.

Goldstein, Joshua S. 2011. Winning the War on War. Hialeah, FI: Dutton/Penguin.

Gurr, Ted Robert. 2000. Ethnic Warfare on the Wane. Foreign Affairs 79 (3):52-64.

Hanson, Robin. 2008. "Catastrophe, Social Collapse, and Human Extinction" in Global Catastrophic Risks, pp. 363-377, ed. Nick Bostrom, and Milan Cirkovic, Oxford University Press.

Hechter, Michael, Timur Kuran, Charles Tilly, Randal Collins, and Edgar Kieser. 1995. Symposium on Prediction in the Social Sciences. American Journal of Sociology 100 (6):1520-615.

Hegre, Håvard, Nils W. Metternich, Håvard Mokleiv Nygård, and Julian Wucherpfennig. 2017. Forecasting in peace research. Journal of Peace Research 54 (2):113-24.

Kuran, Timur. 1989. Sparks and Prairie Fires: A Theory of Unanticipated Revolution. Public Choice 61 (1):41-74. 
Lohmann, Susanne. 1994. The Dynamics of Informational Cascades: The Monday Demonstrations in Leipzig, East Germany, 1989-91. World Politics 47 (1):42-101.

Mueller, John, and Mark G. Stewart. 2015. Chasing Ghosts: The Policing of Terrorism. Oxford and New York: Oxford University Press.

Mueller, John and Mark G. Stewart. 2011. Terror, Security, and Money: Balancing the Risks, Benefits, and Costs of Homeland Security. Oxford and New York: Oxford University Press.

Oneal, John R., and Bruce M. Russett. 2001. Triangulating Peace: Democracy, Interdependence, and International Organizations. New York: Norton.

Pinker, Steven. 2011. The Better Angels of Our Nature: Why Violence has Declined. New York: Viking.

Polo, Sara M T, and Kristian Skrede Gleditsch. 2016. Twisting arms and sending messages Terrorist tactics in civil war. Journal of Peace Research 53 (6):815-29.

Popper, Karl. 1959. The Logic of Scientific Discovery. Camberley: Hutchinson.

Ray, James Lee, and Bruce M. Russett. 1996. The Future as Arbiter of Theoretical Controversies: Predictions, Explanations and the End of the Cold War. British Journal of Political Science 26:441-70.

Richardson, Lewis F. 1948. Variation of the Frequency of Fatal Quarrels with Magnitude. Journal of the American Statistical Association 43 (244):523-46.

Taleb, Nassim Nicholas. 2007. The Black Swan: The Impact of the Highly Improbable. New York: Random House.

Ward, Michael D., and Kristian Skrede Gleditsch. 2002. Location, Location, Location: An MCMC Approach to Modeling the Spatial Context of War and Peace. Political Analysis 10 (3):244-60.

Ward, Michael D., Nils W. Metternich, Cassy L. Dorff, Max Gallop, Florian M. Hollenbach, Anna Schultz, and Simon Weschle. 2013. Learning from the Past and Stepping into the Future: Toward a New Generation of Conflict Prediction. International Studies Review 15 (4):473-90 